\title{
Measuring Patient Trust in Public versus Private Physicians in the Kingdom of Saudi Arabia (KSA)
}

This article was published in the following Dove Press journal:

Journal of Multidisciplinary Healthcare

\section{Afnan Aljaffary (iD \\ Arwa AlThumairi (D) \\ Lojain Almarhoon \\ Ghalyah Alsaawi (iD)}

Department of Health Information Management \& Technology, Imam

Abdulrahman Bin Faisal University (IAU),

Dammam, Kingdom of Saudi Arabia
Correspondence: Afnan Aljaffary

Imam Abdulrahman Bin Faisal University

(IAU), King Faisal Street, Dammam 342I,

Kingdom of Saudi Arabia

Tel +966 I3333| 362

Email aaljaffari@iau.edu.sa
Background: This study aims to assess and compare patient trust in public vs private physicians and to determine the factors that can affect the level of trust in the context of the KSA.

Methods: A cross-sectional study was carried out in the KSA to assess patient trust in physicians. A questionnaire was administered in both Arabic and English to patients above 18 years of age via online channels.

Results: A statistically significant difference was found between the level of trust in public vs private physicians, where the public physicians showed higher patients' trust scores compared to private physicians, where the mean was $2.51(\mathrm{SD}=0.60)$ and $2.29(\mathrm{SD}=0.56)$, respectively, $P$-value $<0.001$. A statistically significant difference was also found between self-assessment health status (SAHS) groups $(\mathrm{F}(3)=11.429, P=0.010)$. Other factors were not significantly associated.

Conclusion: This study found that public physicians engender a higher level of patient trust than private physicians. A further qualitative study should be conducted in the future to investigate the reasons behind the high trust in public physicians in the KSA.

Practice Implications: The results of this study open doors for new investigations that might result in the implementation of new interventions to promote patient trust in the healthcare journey in KSA.

Keywords: patient trust, patient-centered care, trust in physicians, KSA

\section{Background}

Over the years, the dramatic increase in health information sources on the internet has contributed to changing the patient-physician relationship. ${ }^{1}$ Nowadays, treatment plans have become shareable, and patients have become major factors where they are fully engaged in their own plan. ${ }^{2}$

Patient trust is an important concept in healthcare that involves uncertainty and risk. ${ }^{3}$ The concept of trust is defined as the "firm belief in the reliability, truth, or ability of someone or something" by the Oxford English Dictionary. ${ }^{4}$ In healthcare, patient trust has been defined as the patient's confidence in the assumption that their physician is trustworthy and professional enough to treat them. ${ }^{5}$ Trust represents the partnership structure between patient and physician and can depend on communication barriers and people's expectations. ${ }^{6}$ However, better physician communication will enhance and increase the patient's trust and satisfaction. ${ }^{7}$ Evidence from the literature confirms that patient trust is associated with many psychological aspects, since higher trust levels are associated with lower anxiety and higher autonomy in healthcare decision-making. ${ }^{3,8}$ 
The patient's experience can be enhanced through a better understanding of patient trust and by enhancing patient-centeredness. This might result in increasing the patient's adherence to treatment plans, which might positively affect health outcomes. ${ }^{9}$ In addition, increasing patient trust can reduce the demand for seeking second opinions and unnecessary frequent tests and procedures. ${ }^{10}$ This is especially important in the current time, because the Saudi healthcare system is shifting to privatization through the new model of care, whose implementation is beginning in the KSA. Being professionally responsible for patient-centered care, which is one of the six main dimensions of quality of care, is a necessary step for all physicians in order to enhance patient trust within the community. ${ }^{11}$ Patient-centered care is a very important concept, and even the mandatory accrediting bodies in the KSA, namely, the Saudi Central Board for Accreditation of Healthcare Institutes and Joint Commission International, focus on it before issuing accreditation to any hospital. ${ }^{12}$ This is also vital for providers, as it illustrates for them the areas on which they should work to increase patient trust. One of the main factors that influences where treatment is pursued is the type of physician: public or private. Public physicians are employed by a governmental organization, while private physicians are employed by a private organization. ${ }^{6}$ Thus, patient-physician trust is likely to be affected by the type of hospital. ${ }^{6}$

To our knowledge, there is limited available literature concerning patient-physician trust in Saudi Arabia. Consequently, this study will contribute to the literature on how patients' levels of trust might vary between private and public physicians in early stages of a new health reform towards privatization. This research will also enrich the content related to patient trust within the context of the KSA. Thus, the research questions of the current study are; is there a difference between level of patient trust in public and private physicians in KSA?; and what are the characteristics and socio-economic factors influencing level of patient trust in doctors in KSA?

\section{Methods}

\section{Study Design and Tool}

This study used a cross-sectional quantitative design. Patients' trust in physicians was measured using an extant and validated questionnaire. ${ }^{13}$ As most of the target population is Arabic speakers, the questionnaire was translated using backward and forward translation through two certified translators. Both content and face validity were required and applied to both versions of the questionnaire.

Using expert panel review, the content validity of the questionnaire was assessed. Arabic-speaking academic experts from Imam Abdulrahman Bin Faisal University (IAU) and physicians from King Fahd teaching hospital were invited to assess the content validity of the questionnaire. The experts reviewed both the English and the Arabic versions of the questionnaire and thus verified the semantic equivalence. A total of 12 experts were invited via email in February and March 2020 to participate online.

In order to assess face validity, a purposive sampling technique was used on 25 members of the target population. Face validity was determined via one-on-one interviews. In order to indicate maximum variation, potential participants were selected from different age groups, levels of education, and genders.

\section{Participants}

The inclusion criteria were being a patient aged 18 and above living in KSA, speaking English or Arabic. Our local ethics committee approved the study protocol, and all of the participants provided online informed consent. Participants were requested to confirm that they are aged 18 or above and willing to participate in the study before having access to the questionnaire questions.

\section{Recruitment Strategy}

After the content and face validity were carried out, the online questionnaire was designed on Question Pro and distributed online via social media platforms, mainly WhatsApp and Twitter, using a convenience sampling method. Distributing the Patient-Physician Trust Questionnaire via online channels was appropriate given both the aim of our research and the COVID-19 pandemic quarantine implemented during the data collection phase. Recruitment was conducted during March 2020.

\section{Bias}

Recall bias could have been introduced, as the data rely solely on the patient's recollection of their latest contact with their physician.

\section{Study Size}

A study ssize of 345 was deemed to be appropriate for this study based on the rules of thumb provided by Roscoe, 
which state that a sample size between 40 and 500 is considered acceptable for most quantitative studies. ${ }^{14}$ In addition, a similar previous study used a sample size of $288 .^{13}$

\section{Quantitative Variables}

Patients' trust in physicians was assessed through a continuous 1-5 Likert scale by computing the score of all 11 items within the scale (See Appendix A Table 1), with higher scores indicating better shared decision-making.

The patient demographic characteristics assessed in the study included age, gender, occupation, education level, nationality, marital status, current region of residence, whether the patient has health insurance and its type, and the patient's perception of his/her general health.

Information about the patient's last clinical visit was measured, including the type of hospital/clinic (whether public or private).

\section{Results \\ Scale Validity}

An invitation email was sent to 12 experts to ensure the content validity. Six responded to the invitation, representing a $50 \%$ response rate. The assessment of the content validity showed that all items had an acceptable item content validity index (I-CVI), with score above 0.83 , which was considered excellent. ${ }^{15}$ In addition, the findings revealed that the $\mathrm{S}-\mathrm{CVI} / \mathrm{UA}=0.91$ and the $\mathrm{S}-\mathrm{CVI} /$ $A v e=0.98$, which reflect an adequate and satisfactory content validity. ${ }^{15,16}$ Based on these results, few changes were made to the questionnaire.

Overall, the clarity, ability to answer questions, and consistency mean of the face validity form responses was calculated, and the scores were 3.6 and above out of 4 for all 11 items of the questionnaire. As a result, no changes were made.

\section{Characteristics of the Respondents}

The mean age of the patients was 37 years $(\mathrm{SD}=12)$, and the majority of the participants were female $(62 \%)$. The majority of the participants $(63.5 \%)$ had obtained a bachelor's degree and lived in the Eastern province (96.5\%). Most of the participants $(80.6 \%)$ were married. The percentage of patients who chose "very good" as a self-assessment of their health was $71.9 \%$. Insured patients constituted $48.1 \%$ of the total (see Table 1).

\section{Reliability and Item-Total Correlation of the Scale}

The Cronbach's alpha for the patient trust in physicians in the KSA scale was well above the criterion, that is, more than $0.7,{ }^{17}$ with a value of 0.843 . This indicated that the scale had a high level of internal consistency with the sample used. All the items met the homogeneity criteria (ie, $r<0.3$ ). Thus, they were associated with the same dimension, and no items were identified as redundant (ie, $\mathrm{r}>0.9) .{ }^{18}$ For this reason, all the items of the questionnaire were retained.

\section{Description of the Total Scores of the Questionnaire}

The patient trust score was right-skewed, and there were more respondents in the lower trust region, and with fewer respondents in the high trust region. Using the ShapiroWilk test, the scale is not normally distributed ( $P$ value $=0.001)$. The median of the patient trust score was $26(\mathrm{IQR}=7)$, and the maximum value was 55 , while the minimum was 11 .

\section{Subgroup Differences in Patient Trust in Physicians in the KSA}

Based on the sufficient sample size, the assumption of the normal distribution is not required to use both tests, oneway ANOVA test and the $t$-test. ${ }^{19,20}$ A normality analysis was done (Figures 1, Figures 2-3), and it shows that the number of outliers was similar for variables with two groups (hospital type, insurance status, and gender), and the median and mean level of trust were close. However, for variables with more than two groups the ANOVA assumptions for equal variance were preached, therefore an independent-samples Kruskal-Wallis test was used (see Table 2).

There was a statistically significant difference in the patient trust score between public and private physicians (t-value $=3.447, P$-value $=0.001)$. Patients who receive care from public physicians have a higher trust mean score (mean=2.51, $\mathrm{SD}=0.6$ ) than patients receiving care from private physicians (mean $=2.29, \mathrm{SD}=0.59$; see Table 2).

In addition, there were statistically significant differences between self-assessment health status (SAHS) groups' means of trust as determined by Kruskal-Wallis Test $(\mathrm{F}(3)=11.429, \quad P=0.010)$. After performing the Games-Howell post hoc test, statistically significant differences were found between patients with a "very good" 
Table I Characteristics of the Participants

\begin{tabular}{|c|c|}
\hline Characteristics & n (\%) \\
\hline \multicolumn{2}{|l|}{ Gender $(n=345)$} \\
\hline Female & $214(62.0)$ \\
\hline Male & $|3|(38.0)$ \\
\hline Age, mean D $(n=345)$ & $37.01 \pm 12$ \\
\hline \multicolumn{2}{|l|}{ Education level $(n=345)$} \\
\hline Secondary school or less & $77(22.3)$ \\
\hline Diploma & $40(11.6)$ \\
\hline Bachelor's degree & $219(63.5)$ \\
\hline Post-graduate degree & $9(2.6)$ \\
\hline \multicolumn{2}{|l|}{ Occupation $(n=345)$} \\
\hline Not employed & $162(47)$ \\
\hline Employee in healthcare sector & $29(8.4)$ \\
\hline Employee in other sectors & I54 (44.6) \\
\hline \multicolumn{2}{|l|}{ Monthly income $(n=345)$} \\
\hline I do not have regular income & III (32.2) \\
\hline Less than $5,000 \mathrm{SR}$ & $36(10.4)$ \\
\hline $5,000-9,999$ SR & $27(7.8)$ \\
\hline $10,000-14,999$ SR & $65(18.8)$ \\
\hline 15,000-19,999 SR & $47(13.6)$ \\
\hline 20,000 SR and above & $25(7.2)$ \\
\hline Prefer not to say & $34(9.9)$ \\
\hline \multicolumn{2}{|l|}{ Marital status $(n=345)$} \\
\hline Single & $60(17.4)$ \\
\hline Married & $278(80.6)$ \\
\hline Divorced, widowed, or separated & $7(2)$ \\
\hline \multicolumn{2}{|l|}{ Insurance status $(n=345)$} \\
\hline Insured & $179(5 \mid .9)$ \\
\hline Uninsured & $166(48.1)$ \\
\hline \multicolumn{2}{|l|}{ Insurance class $(n=166)$} \\
\hline Class A & $110(66.3)$ \\
\hline Class B & $28(16.9)$ \\
\hline Class $C$ and below & $12(7.2)$ \\
\hline Others & $16(9.6)$ \\
\hline \multicolumn{2}{|l|}{ SAHS $(n=345)$} \\
\hline Very good & 248 (7I.9) \\
\hline Good & $83(24.1)$ \\
\hline Poor or very poor & $9(2.6)$ \\
\hline Prefer not to say & $5(1.4)$ \\
\hline
\end{tabular}

Abbreviations: $n$, sample size; SD, standard deviation; SR, Saudi Riyals; SAHS, selfassessed health status.

SAHS and patients with a "good" SAHS ( $P$-value $=0.022)$. The higher trust level was for participants with a "good" SAHS.

According to the results of the SPSS analysis, it appears that there is no significant difference between the categories of the other following characteristics (age, gender, marital status, education level, monthly income, insurance status, and occupation). Therefore, it ought to be mentioned that these characteristics may have a minimum effect that is not large enough to be considered or may have no effect.

Using the multivariable linear regression with a Rvalue equal to $0.304(30 \%)$ with 21 degrees of freedom of the study variable been explained in the model and $P$ value $=0.055$. The collinearity between variables were all above 0.7 , which is acceptable and proves the variable fit in the model follows the model assumptions. ${ }^{21}$

There is a significant relation between type of hospital and mean level of patient trust, $\mathrm{t}$-score $=-2.262, P$ value $=0.024(95 \% \mathrm{CI}=-0.351$ to -0.024$)$ after adjusting for all patient characteristics (see Table 3). Patients who were treated in private hospitals had a significantly lower score than those who were treated in public hospitals. SAHA class also has a significant relation with mean level of patient trust after adjusting for the other patient characteristics, especially for patients who have reported "good" and "poor" with a t-score $=2.040, P$-value $=0.042$ $(95 \% \mathrm{CI}=0.0060 .316)$ and $\mathrm{t}$-score $=3.084, P$-value $=0.002$ (95\% CI $=0.102-0.461)$, respectively (see Table 3 ). Patients who have reported themself as "good" or "poor" had a significantly higher trust score than a patient who reported themself as having "very good".

\section{Discussion and Conclusion}

This study investigated patient-physician trust in the context of the healthcare system of the KSA. Patient-physician trust is a core relationship that will feed the theoretical literature. The obtained results clearly indicate that physicians working in public hospitals were more likely to have a higher level of patient trust compared to other physicians who were working in private hospitals. Two previous studies, one conducted in Cambodia and one in Australia, produced the same results. ${ }^{6,22}$ This might be due to the similarity in the healthcare systems of the KSA and these two countries, all of them have a two-tiered health system, that is, private and public healthcare sectors. The perception of why private physicians have lower patient trust is not explored in our study, but it might be because patients feel that they are a source of profit and considered as a "number", rather than as a patient in need of treatment. ${ }^{23}$

Interestingly, participants with "good" SAHS showed a higher level of trust. In contrast, participants with a "very good" SAHS were shown to have a lower trust level. This 


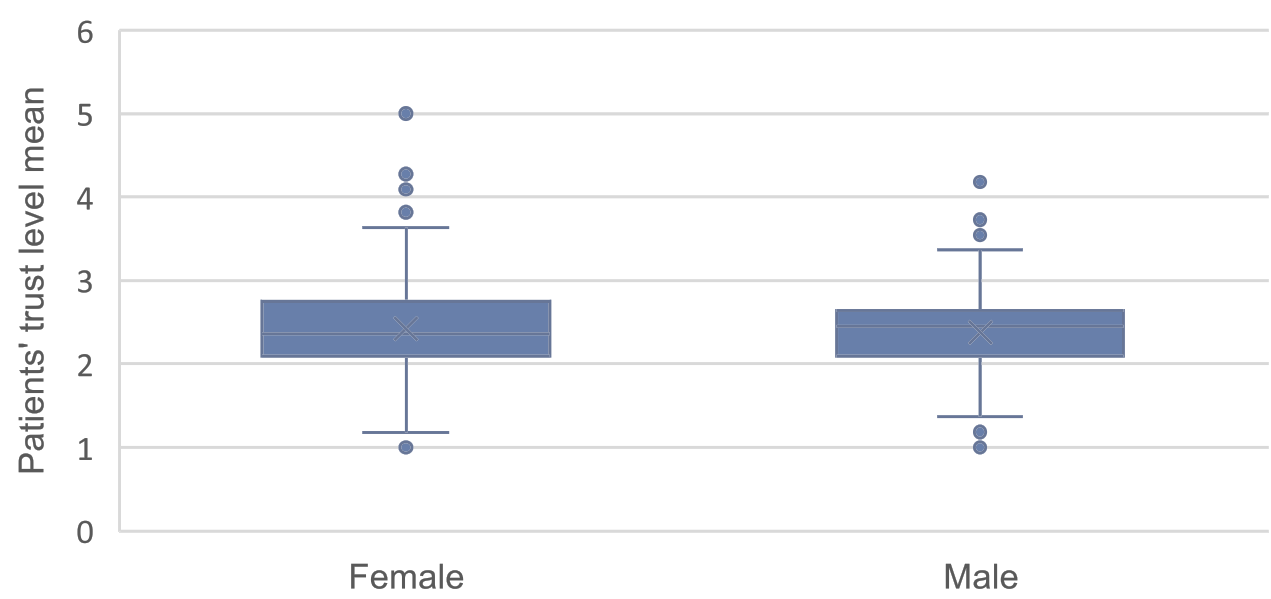

Gender

Figure I Stem and leaf test between gender and mean of patient trust level.

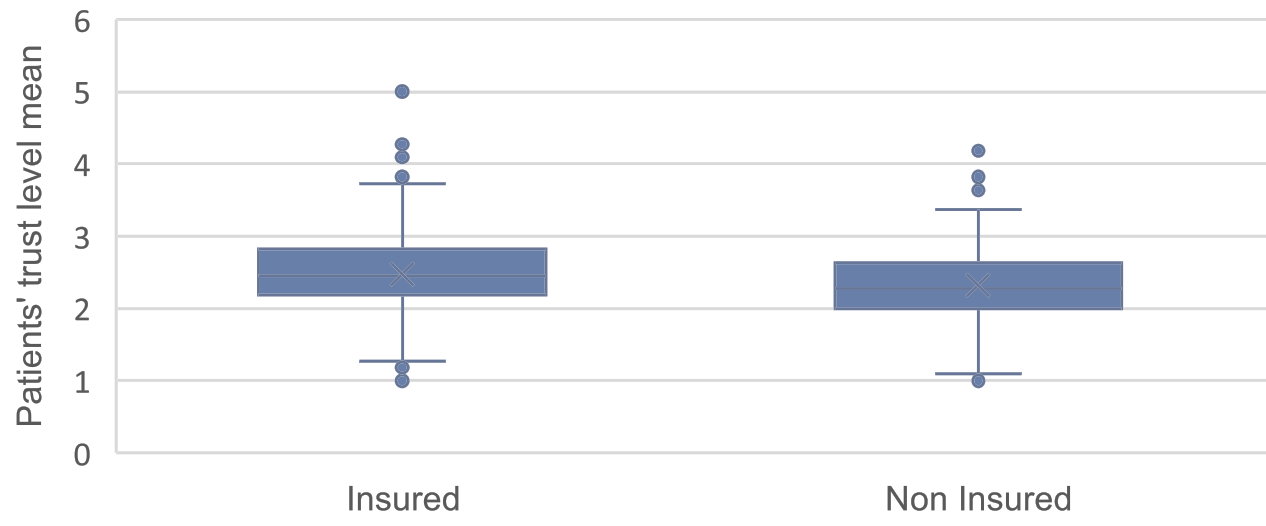

Insurance Status

Figure 2 Stem and leaf test between insurance status and mean level of trust.

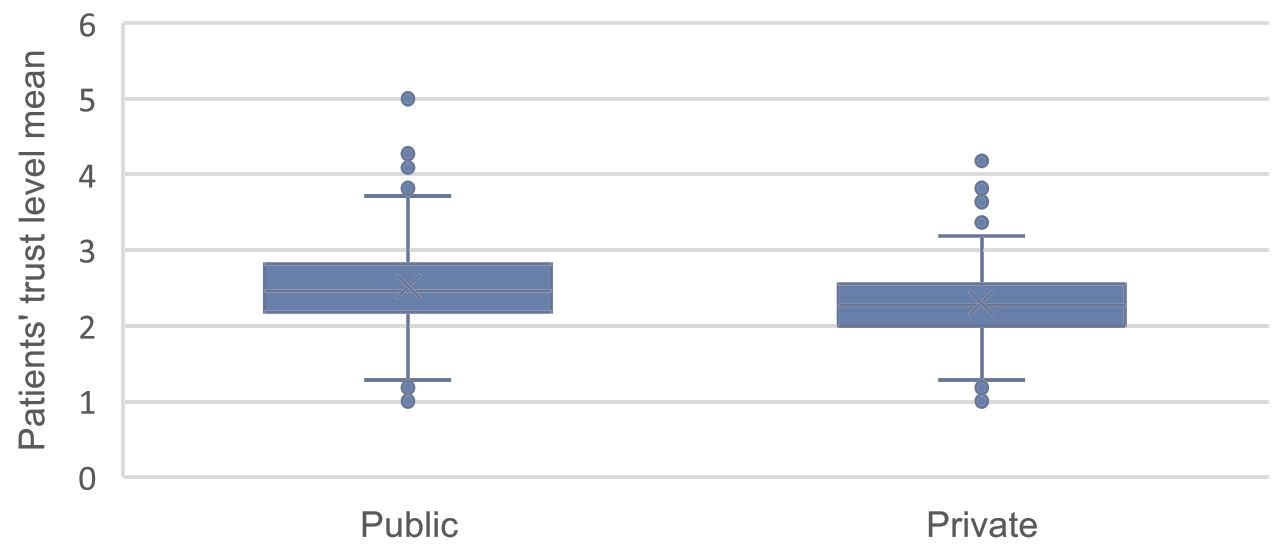

HospitalType

Figure 3 Stem and leaf test between hospital type and mean level of patient trust. 
Table 2 Differences Between Age, Gender, Hospital Type, Insurance Status, Marital Status, SAHS, Education Level, Monthly Income, Insurance Class, and Occupation Categories and Mean Patient's Trust Score

\begin{tabular}{|c|c|c|c|c|}
\hline Variables & $\mathbf{n}$ & Mean & SD & Test \\
\hline \multicolumn{5}{|l|}{ Hospital type } \\
\hline Public & 170 & 2.51 & 0.60 & \multirow[t]{2}{*}{$t=3.447, P=0.001$} \\
\hline Private & 175 & 2.29 & 0.56 & \\
\hline Age & 345 & 2.40 & 0.60 & $\begin{array}{l}\text { Pearson correlation }= \\
-0.026 \\
P=0.636\end{array}$ \\
\hline \multicolumn{5}{|l|}{ Gender } \\
\hline Female & 214 & 2.42 & 0.59 & \multirow[t]{2}{*}{$t=0.725, P=0.954$} \\
\hline Male & 131 & 2.37 & 0.60 & \\
\hline \multicolumn{5}{|l|}{ Insurance status } \\
\hline Insured & 179 & 2.47 & 0.60 & \multirow{2}{*}{$t=2.413, P=0.994$} \\
\hline Uninsured & 166 & 2.32 & 0.57 & \\
\hline \multicolumn{5}{|l|}{ Marital status } \\
\hline Single & 60 & 2.45 & 0.60 & \multirow[t]{3}{*}{$F(2)=0.282, P=0.868$} \\
\hline Married & 278 & 2.38 & 0.57 & \\
\hline $\begin{array}{l}\text { Divorced, widowed, or } \\
\text { separated }\end{array}$ & 7 & 2.59 & 1.16 & \\
\hline \multicolumn{5}{|l|}{ SAHS } \\
\hline Very good & 248 & 2.33 & 0.55 & \multirow[t]{4}{*}{$F(3)=11.429, P .010$} \\
\hline Good & 83 & 2.54 & 0.58 & \\
\hline Poor or very poor & 8 & 2.79 & 0.86 & \\
\hline Prefer not to say & 6 & 2.59 & 1.43 & \\
\hline \multicolumn{5}{|l|}{ Education level } \\
\hline Secondary school or less & 77 & 2.41 & 0.60 & \multirow[t]{4}{*}{$F(3)=1.835, P=0.607$} \\
\hline Diploma & 40 & 2.46 & 0.49 & \\
\hline Bachelor's degree & 219 & 2.39 & 0.62 & \\
\hline Post-graduate degree & 9 & 2.27 & 0.39 & \\
\hline \multicolumn{5}{|l|}{ Monthly income } \\
\hline $\begin{array}{l}\text { I do not have regular } \\
\text { income }\end{array}$ & 111 & 2.43 & 0.54 & \multirow[t]{7}{*}{$F(6)=2.321, P=0.888$} \\
\hline Less than $5,000 \mathrm{SR}$ & 36 & 2.40 & 0.53 & \\
\hline 5,000 SR to 9,999 SR & 27 & 2.41 & 0.54 & \\
\hline 10,000 SR to 14,999 SR & 65 & 2.33 & 0.65 & \\
\hline 15,000 SR to 19,999 SR & 47 & 2.42 & 0.58 & \\
\hline 20,000 SR and above & 25 & 2.39 & 0.50 & \\
\hline Prefer not to say & 34 & 2.40 & 0.81 & \\
\hline \multicolumn{5}{|l|}{ Insurance class } \\
\hline Class A & 110 & 2.28 & 0.56 & \multirow[t]{4}{*}{$F(3)=3.159, P=0.368$} \\
\hline Class B & 28 & 2.44 & 0.51 & \\
\hline Class $C$ and below & 12 & 2.55 & 0.76 & \\
\hline Others & 16 & 2.17 & 0.69 & \\
\hline \multicolumn{5}{|l|}{ Occupation } \\
\hline Not employed & 162 & 2.42 & 0.59 & \multirow[t]{3}{*}{$F(2)=1.826, p$ P. .01} \\
\hline $\begin{array}{l}\text { Employee in healthcare } \\
\text { sector }\end{array}$ & 29 & 2.29 & 0.47 & \\
\hline Employee in other sectors & 154 & 2.39 & 0.62 & \\
\hline
\end{tabular}

Abbreviations: $\mathrm{n}$, sample size; $\mathrm{SD}$, standard deviation; $t$, $t$-test value; $\mathrm{P}, \mathrm{P}$-value; $\mathrm{f}, \mathrm{f}$ value; SAHS, self-assessed health status; SR, Saudi Riyals. conflicts with the findings of Kim et $\mathrm{al}^{24}$ and Croker et al. ${ }^{25}$ These studies found that the relationship between the level of patient trust and SAHS is positive; that is, the higher the reported SAHS rating, the greater the likelihood of a higher level of trust. Croker et al ${ }^{25}$ conducted their study based on a larger sample size, which explains the difference in findings compared to our study.

Based on the results, the factors that showed no association with level of patient trust are gender, age, educational level, marital status, occupation, insurance status, insurance class, and monthly income. The lack of association between some of these factors and level of patient trust has been found in many different previous studies. ${ }^{24,26}$

\section{Study Limitations}

There are some factors affecting the generalizability of the current study. Some of the group characteristics are represented by a low number of participants, such as non-Saudis. In addition, since the questionnaire was distributed online, people with limited access to the internet, such as elderly and poor patients, might be less likely to participate in this online questionnaire. Furthermore, the study used a convenience sampling method due to the COVID-19 pandemic situation, resulting in a possibly biased and less reliable sample. ${ }^{27}$ However, several studies have used the same methods of the current study, ie, questionnaire online distribution using convenience sampling technique. ${ }^{28,29}$ This gives an indication that this became a common method during the pandemic in scientific research studies.

We recommend conducting qualitative research in future studies in order to dig deeper into the reasons behind patient trust in physicians in the KSA. This will help provide corrective interventions for policymakers in the KSA.

\section{Practice Implications}

The results of this study open doors for new investigations that might result in the implementation of new interventions and policies to promote patient trust in the healthcare journey. Such knowledge will help determine the best practice in the government sector in the KSA and ensure better trust in the private sector in order to shift towards privatization in the best manner possible. We need several steps until we reached patient's trust practical implication because it's behavioral. However, physicians are more likely to be trusted by their patients if they follow practical implications such as: showing 
Table 3 Multivariable Linear Regression Assessing Differences Between Age, Gender, Hospital Type, Insurance Status, Marital Status, SAHS, Education Level, Monthly Income, Insurance Class, and Occupation Categories and Mean Patient's Trust Score

\begin{tabular}{|c|c|c|c|c|c|c|c|}
\hline \multirow[t]{2}{*}{ Patient Characteristics } & \multicolumn{2}{|c|}{$\begin{array}{l}\text { Unstandardized } \\
\text { Coefficients }\end{array}$} & \multirow{2}{*}{$\begin{array}{l}\text { Standardized Coefficients } \\
\text { Beta }\end{array}$} & \multirow[t]{2}{*}{$\mathbf{t}$} & \multirow[t]{2}{*}{ Sig. } & \multicolumn{2}{|c|}{ 95\% Confidence Interval for B } \\
\hline & Beta & Std. Error & & & & Lower Bound & Upper Bound \\
\hline (Constant) & 2.798 & 0.260 & & 10.767 & 0.000 & 2.287 & 3.309 \\
\hline \multicolumn{8}{|l|}{ Hospital Type } \\
\hline Public & 1.00 (ref) & & & & & & \\
\hline Private & -0.188 & 0.083 & -0.157 & -2.262 & $0.024^{*}$ & -0.351 & -0.024 \\
\hline \multicolumn{8}{|l|}{ Gender } \\
\hline Female & 1.00 (ref) & & & & & & \\
\hline Male & -0.071 & 0.092 & -0.058 & -0.773 & 0.440 & -0.253 & 0.110 \\
\hline Age & -0.004 & 0.004 & -0.074 & -1.001 & 0.317 & -0.011 & 0.004 \\
\hline \multicolumn{8}{|l|}{ Insurance Status } \\
\hline Insured & 1.00 (ref) & & & & & & \\
\hline Uninsured & -0.062 & 0.092 & -0.052 & -0.675 & 0.500 & -0.244 & 0.119 \\
\hline \multicolumn{8}{|l|}{ Marital status } \\
\hline Single & 1.00 (ref) & & & & & & \\
\hline Married & -0.036 & 0.101 & -0.024 & -0.361 & 0.718 & -0.234 & 0.162 \\
\hline Divorced, widowed, or separated & 0.051 & 0.133 & 0.023 & 0.385 & 0.700 & -0.211 & 0.314 \\
\hline \multicolumn{8}{|l|}{ SAHS } \\
\hline Very good & 1.00 (ref) & & & & & & \\
\hline Good & 0.161 & 0.079 & 0.133 & 2.040 & $0.042^{*}$ & 0.006 & 0.316 \\
\hline Poor or very poor & 0.281 & 0.091 & 0.201 & 3.084 & $0.002^{*}$ & 0.102 & 0.461 \\
\hline Prefer not to say & 0.450 & 0.242 & 0.106 & 1.857 & 0.064 & -0.027 & 0.926 \\
\hline \multicolumn{8}{|l|}{ Education level } \\
\hline Secondary school or less & 1.00 (ref) & & & & & & \\
\hline Diploma & 0.164 & 0.126 & 0.088 & 1.300 & 0.194 & -0.084 & 0.411 \\
\hline Bachelor's degree & 0.046 & 0.087 & 0.037 & 0.532 & 0.595 & -0.124 & 0.217 \\
\hline Post-graduate degree & -0.014 & 0.218 & -0.004 & -0.066 & 0.948 & -0.444 & 0.415 \\
\hline \multicolumn{8}{|l|}{ Monthly income } \\
\hline I do not have regular income & 1.00 (ref) & & & & & & \\
\hline Less than $5,000 \mathrm{SR}$ & -0.106 & 0.120 & -0.054 & -0.881 & 0.379 & -0.341 & 0.130 \\
\hline $5,000-9,000$ SR & 0.003 & 0.133 & 0.001 & 0.022 & 0.982 & -0.259 & 0.265 \\
\hline $10,000-14,000$ SR & -0.046 & 0.115 & -0.030 & -0.397 & 0.692 & -0.272 & 0.181 \\
\hline $15,000-19,999$ SR & 0.027 & 0.135 & 0.015 & 0.199 & 0.842 & -0.238 & 0.292 \\
\hline 20,000 SR or above & 0.077 & 0.166 & 0.034 & 0.466 & 0.641 & -0.249 & 0.403 \\
\hline Prefer not to say & -0.012 & 0.126 & -0.006 & -0.097 & 0.923 & -0.260 & 0.235 \\
\hline \multicolumn{8}{|l|}{ Insurance class } \\
\hline Class A & 1.00 (ref) & & & & & & \\
\hline Class B & 0.039 & 0.118 & 0.018 & 0.330 & 0.742 & -0.193 & 0.271 \\
\hline Class $C$ and below & 0.400 & 0.366 & 0.123 & 1.094 & 0.275 & -0.319 & 1.119 \\
\hline Others & -0.131 & 0.160 & -0.046 & -0.821 & 0.412 & -0.447 & 0.184 \\
\hline \multicolumn{8}{|l|}{ Occupation } \\
\hline Not employed & 1.00 (ref) & & & & & & \\
\hline Employee in Health sector & 0.117 & 0.127 & 0.054 & 0.921 & 0.358 & -0.133 & 0.368 \\
\hline Employee in other health sector recode & -0.306 & 0.405 & -0.082 & -0.756 & 0.450 & -1.103 & 0.491 \\
\hline
\end{tabular}

Abbreviations: Std. Error, standard error; Sig, significance; $t$, $t$-test value; B, beta; *, Significance; SAHS, self-assessed health status; SR, Saudi Riyals. 
respect, competence in knowledge, competence in communication skills, being honest, maintaining confidentiality, and caring. ${ }^{30}$ Moreover, according to the World Health Organization (WHO) patient engagement helps of preserving trust between patients and physicians. ${ }^{31}$

\section{Ethical Approval}

This research study was approved by the institutional review board at Imam Abdulrahman University, KSA. The IRB number is: IRB-UGS-2020-03-057. This study was conducted in accordance with the Declaration of Helsinki.

\section{Informed Consent}

The authors affirm that all personal identifiers have been removed so that participating patients are not identifiable and cannot be identified through narrative details.

\section{Funding}

This research did not receive any specific grant from funding agencies in the public, commercial, or not-forprofit sectors.

\section{Disclosure}

The authors report no conflicts of interest for this work.

\section{References}

1. Ganesh K. Patient-doctor relationship: changing perspectives and medical litigation. Indian J Urol. 2009;25(3):356-360. doi:10.4103/09701591.56204

2. Chandra S, Mohammadnezhad M, Ward P. Trust and communication in a doctor- patient relationship: a literature review. $J$ Health Commun. 2018;3-36. doi:10.4172/2472-1654.100146

3. Allinson M, Chaar B. How to build and maintain trust with patients. Pharm J. 2016;297:300-303.

4. Lexico. Definition of trust. Available from: https://www.lexico.com/ definition/trust. Accessed March 11, 2020.

5. Fiscella K, Meldrum S, Franks P, et al. Patient trust: is it related to patient-centered behavior of primary care physicians? Med Care. 2004;42(11):1049-1055. doi:10.1097/00005650-200411000-00003

6. Ozawa S, Walker DG. Comparison of trust in public vs private health care providers in rural Cambodia. Health Policy Plan. 2011;26(Suppl 1):i20-9. doi:10.1093/heapol/czr045

7. Tongue JR, Epps HR, Forese LL, et al. Communication skills for patient-centered care: research-based, easily learned techniques for medical interviews that benefit orthopaedic surgeons and their patients. J Bone Joint Surg Am. 2005;87(3):652-658. doi:10.2106/00004623200503000-00027

8. Piippo J, Aaltonen J. Mental health care: trust and mistrust in different caring contexts. J Clin Nurs. 2008;17(21):2867-2874. doi:10.1111/ j.1365-2702.2007.02270.x

9. Lee YY, Lin JL. How much does trust really matter? A study of the longitudinal effects of trust and decision-making preferences on diabetic patient outcomes. Patient Educ Couns. 2011;85(3):406-412. doi:10.1016/j.pec.2010.12.005
10. Hall MA, Camacho F, Dugan E, Balkrishnan R. Trust in the medical profession: conceptual and measurement issues. Health Serv Res. 2002;37(5):1419-1439. doi:10.1111/1475-6773.01070

11. Institute of Medicine (US) Committee on Quality of Health Care in America. Crossing the Quality Chasm: A New Health System for the 21st Century. National Academies Press (US); 2001.

12. Saudi Central Board for Accreditation of Healthcare Institutions. The relationship between accreditation and improvement of patient care; 2019. Available from: https://portal.cbahi.gov.sa/Library/Assets/AIP \%20AR.compressed-105955.pdf. Accessed 22 July 2020.

13. Kalsingh MJ, Veliah G, Gopichandran V. Psychometric properties of the trust in physician scale in Tamil Nadu, India. J Family Med Prim Care. 2017;6(1):34-38. doi:10.4103/2249-4863.214966

14. Roscoe JT. Fundamental Research Statistics for the Behavioral Sciences. 2nd ed. New York: Holt, Rinehart and Winston; 1975.

15. Polit DF, Beck CT, Owen SV. Is the CVI an acceptable indicator of content validity? Appraisal and recommendations. Res Nurs Health. 2007;30(4):459-467. doi:10.1002/nur.20199

16. Shi J, Mo X, Sun Z. [Content validity index in scale development]. Zhong Nan Da Xue Xue Bao Yi Xue Ban. 2012;37(2):152-155. doi:10.3969/j.issn.1672-7347.2012.02.007. Chinese

17. Streiner DL, Norman GR. Health Measurement Scales: A Practical Guide to Their Development and Use. 4th ed. New York: Oxford University Press; 2008.

18. Tavakol M, Dennick R. Making sense of Cronbach's alpha. Int J Med Educ. 2011;2:53-55. doi:10.5116/ijme.4dfb.8dfd

19. Blanca MJ, Alarcón R, Arnau J, Bono R, Bendayan R. Non-normal data: is ANOVA still a valid option? Psicothema. 2017;29(4):552557. doi:10.7334/psicothema2016.383

20. Lumley T, Diehr P, Emerson S, Chen L. The importance of the normality assumption in large public health data sets. Annu Rev Public Health. 2002;23(1):151-169. doi:10.1146/annurev. publhealth.23.100901.140546

21. Bowerman BL, O'connell RT. Linear Statistical Models: An Applied Approach. Brooks/Cole; 1990.

22. Ward PR, Rokkas P, Cenko C, et al. A qualitative study of patient (dis) trust in public and private hospitals: the importance of choice and pragmatic acceptance for trust considerations in South Australia. BMC Health Serv Res. 2015;15(1):1-12. doi:10.1186/s12913-0150967-0

23. Shaya B, Al Homsi N, Eid K, et al. Factors associated with the public's trust in physicians in the context of the Lebanese healthcare system: a qualitative study. BMC Health Serv Res. 2019;19(1):525534. doi:10.1186/s12913-019-4354-0

24. Kim AM, Bae J, Kang S, et al. Patient factors that affect trust in physicians: a cross-sectional study. BMC Fam Pract. 2018;19(1):187. doi:10.1186/s12875-018-0875-6

25. Croker JE, Swancutt DR, Roberts MJ, Abel GA, Roland M, Campbell JL. Factors affecting patients' trust and confidence in GPs: evidence from the English national GP patient survey. BMJ Open. 2013;3(5):e002762. doi:10.1136/bmjopen-2013-002762

26. Baidya M, Gopichandran V, Kosalram K. Patient-physician trust among adults of rural Tamil Nadu: a community-based survey. $J$ Postgrad Med. 2014;60(1):21-26. doi:10.4103/0022-3859.128802

27. Hedt BL, Pagano M. Health indicators: eliminating bias from convenience sampling estimators. Stat Med. 2011;30(5):560-568. doi:10.1002/sim.3920

28. Geldsetzer P. Knowledge and perceptions of COVID-19 among the general public in the United States and the United Kingdom: a crosssectional online survey. Ann Intern Med. 2020;173(2):157-160. doi:10.7326/M20-0912

29. Khasawneh AI, Humeidan AA, Alsulaiman JW, et al. Medical students and COVID-19: knowledge, attitudes, and precautionary measures. a descriptive study from Jordan. Front Public Health. 2020;8:253-262. doi:10.3389/fpubh.2020.00253 
30. Allinson M, Chaar B. How to build and maintain trust with patients. Pharm J. 2016;297. Available from: https://www.pharmaceutical-jour nal.com/cpd-and-learning/learning-article/how-to-build-and-main tain-trust-with-patients/20201862.article?firstPass=false
31. Patient Engagement. 2016. Available from: https://apps.who.int/iris/ bitstream/handle/10665/252269/9789241511629-eng.pdf. Accessed December 5, 2020.

\section{Publish your work in this journal}

The Journal of Multidisciplinary Healthcare is an international, peerreviewed open-access journal that aims to represent and publish research in healthcare areas delivered by practitioners of different disciplines. This includes studies and reviews conducted by multidisciplinary teams as well as research which evaluates the results or conduct of such teams or healthcare processes in general. The journal covers a very wide range of areas and welcomes submissions from practitioners at all levels, from all over the world. The manuscript management system is completely online and includes a very quick and fair peer-review system. Visit http://www.dovepress.com/testimonials. php to read real quotes from published authors. 